\title{
Geochemical controls on the elemental composition of siderite: Implications for palaeo-environmental reconstructions
}

\section{Abstract}

10 The elemental composition of siderite $\left(\mathrm{FeCO}_{3}\right)$ has been widely used as a palaeo-environmental

\author{
Ritwika Sengupta $^{{ }^{*}}$, Nicholas J. Tosca ${ }^{1}$, Stuart A. Robinson ${ }^{1}$ \\ ${ }^{1}$ Department of Earth Sciences, University of Oxford, South Parks Road, Oxford, OX1 3AN \\ ${ }^{*}$ Corresponding author: ritwika.sengupta@earth.ox.ac.uk \\ *Telephone:+44 (0) 7919376071
} proxy, and commonly utilised in the diagnosis of marine influences on Phanerozoic coastal wetland sediments. That siderite might reflect marine or freshwater sources is based on the premise that a marine origin should show an enrichment of $\mathrm{Ca}$ and/or $\mathrm{Mg}$, while high concentrations of $\mathrm{Mn}$ should reflect precipitation from freshwater. However, the main controls on the elemental composition of siderite, and the degree to which siderite composition reflects parent water chemistry, are poorly understood. To address these issues, we conducted siderite nucleation and seeded growth experiments to examine element partitioning at a variety of saturation states and solution compositions (i.e., cation concentrations, $\mathrm{pH}$, and $\mathrm{pCO}_{2}$ ). Results indicate a strong preference for Mn uptake over $\mathrm{Ca}$ and $\mathrm{Mg}$, even when $\mathrm{Mn}$ is present at concentrations far below those of $\mathrm{Ca}$ or Mg. This uptake is enhanced at slower growth rates and lower saturation states, which may, in part, reflect surface structural controls on uptake and or a change in the dominant growth mechanism. Ca uptake only occurred during nucleation experiments, while measurable Mg uptake was not observed in experiments conducted at $20^{\circ} \mathrm{C}$, but increased slightly at $55^{\circ} \mathrm{C}$. These results suggest that the chemical composition of siderite does not directly reflect aqueous cation chemistry as previously assumed and is strongly influenced by kinetics rather than equilibrium behaviour. This leads us to conclude that variations in pore water chemistry alone cannot explain the range of $\mathrm{Ca}$ and $\mathrm{Mg}$ concentrations reported from geological siderites, and that other factors must be considered (such as physical admixtures of multiple carbonate minerals and/or the products of diagenetic recrystallization). 


\section{Introduction}

Siderite $\left(\mathrm{FeCO}_{3}\right)$ is found in sedimentary rocks throughout geological time, notably as a constituent of Precambrian banded iron formations (BIFs), and in many sandstones, fine-grained siliciclastics, carbonates, and pedogenic nodules spanning the Precambrian and Phanerozoic (Bahrig, 1989; Choi et al., 2003; Johnson et al., 2008; Lim et al., 2004; Ludvigson et al., 1998; Pye et al., 1990; Robinson et al., 2010; Ufnar et al., 2004a, 2004b; Weibel et al., 2016). Of these deposits, early diagenetic siderite spheres (or "sphaerosiderites"), occurring within a range of strata deposited in dominantly non-marine environments (Ludvigson et al., 1998; Ufnar et al., 2004a; Ludvigson et al., 2013), are perhaps among the most studied examples of siderite precipitation of the Phanerozoic.

As sphaerosiderites are thought to grow in wetland soils, they are considered to be important archives of the continental hydrological system by providing a record of the $\delta^{18} \mathrm{O}$ of meteoric groundwater (Mozley and Wersin, 1992; Ludvigson et al., 1998; Choi et al., 2003; Ufnar et al., 2004a; Choi and Kim, 2006; Suarez et al., 2009; Robinson et al., 2010; Ludvigson et al., 2013). As a consequence, unravelling the precise nature of pore waters, from which sphaerosiderites precipitated, has persisted as a major research goal. Indeed, the elemental composition of sphaerosiderites has been extensively used to infer freshwater, brackish or marine porewater conditions, in order to identify those samples likely to record a meteoric groundwater signal (Fisher et al., 1998; Choi et al., 2003; Lim et al., 2004; Ufnar et al., 2004a; Ufnar et al., 2004b; Driese et al., 2004; Robinson et al., 2010; Ludvigson et al., 2013; Weibel et al., 2016). For example, based on sedimentological studies of siderite-bearing strata, sphaerosiderites with more extensive $\mathrm{Ca}$ and $\mathrm{Mg}$ substitution are considered to reflect a marine influence, while higher concentrations of $\mathrm{Mn}$ compared to $\mathrm{Ca}$ or $\mathrm{Mg}$ are commonly interpreted to reflect freshwater conditions (Mozley, 1989; Ludvigson et al., 1998; Driese et al., 2010).

Previous investigations of Phanerozoic sphaerosiderites have therefore implicitly assumed that the elemental composition of siderite should reflect the chemistry of the growth solution (i.e. palaeo pore waters). However, this assumption is not easily reconciled with laboratory syntheses, which 
have failed to reproduce the compositional link between siderite and pore water chemistry (Thornber and Nickel, 1976; Carothers et al., 1988; Mortimer et al., 1997; Jimenez-Lopez and Romanek, 2004; Romanek et al., 2009). Previous studies have examined controls on siderite chemical composition particularly in reference to $\mathrm{Ca}$ and $\mathrm{Mg}$. However, experimental conditions are typically associated with crystallisation rates that may be orders of magnitude higher than natural settings (Postma, 1980; Pye et al., 1990; Steinmann and Shotyk, 1997). In contrast, chemical controls on Mn uptake in siderite have not been well constrained, particularly for low supersaturation growth conditions. Mn is often a dominant component in siderite, but comparatively little is known about palaeo-environmental factors leading to the common observations of typically Mn-rich siderites (Fisher et al., 1998; Choi et al., 2003; Lim et al., 2004; Weibel et al., 2016). Similarly, the significance of Mg-rich compositions, and associated changes in Ca reported in ancient sphaerosiderites (Mozley and Wersin, 1992; Fisher et al., 1998; Khim et al., 1999; Khim et al., 2000; Choi et al., 2003; Lim et al., 2004), are poorly understood in the context of laboratory experiments (Thornber and Nickel, 1976; Mortimer et al., 1997; Romanek et al., 2009), which have been unable to reproduce natural concentrations of $\mathrm{Mg}$ in siderite. Although the latter observation has been intuitively ascribed to the influence of marine waters (Mozley, 1989; Choi et al., 2003; Ufnar et al., 2004a; Choi and Kim, 2006; Suarez et al., 2009; Robinson et al., 2010; Ludvigson et al., 2013; Weibel et al., 2016), the rates and mechanisms of element incorporation during siderite nucleation and growth are not fully understood. Constraining the factors influencing elemental composition of siderite is critical as a means of understanding the growth conditions and assessing the potential of a given sedimentary deposit to yield robust constraints on palaeoclimate.

The goal of this study is to address these issues through an experimental investigation of the controls on the chemical composition of inorganically-precipitated siderite. In particular, our experiments extend to relatively low saturation states and, hence, growth rates which may more closely represent wetland systems in which modern and ancient siderite growth has occurred. We present results from nucleation and growth experiments investigating a range of factors, such as $\mathrm{pCO}_{2}$, salinity, cation concentration, temperature, and $\mathrm{pH}$. We then discuss, in light of our results, 
84 the principal factors controlling the elemental composition of siderite in natural and synthetic systems. Finally, we review geological processes that may further modify the elemental composition of sphaerosiderite in sedimentary systems, in order to provide a process-based framework to aid in

87 their robust paleo-environmental interpretation.

\section{Methods}

Two types of siderite precipitation experiments were conducted; homogeneous nucleation

90 (where siderite was spontaneously precipitated directly from solution) and seeded growth (where

91 siderite overgrowths were precipitated on to pre-existing seed material). These two experiment

92 types can be distinguished on the basis of saturation state, which is controlled by concentration of

$93 \mathrm{Fe}^{2+}, \mathrm{pCO}_{2}$ (or total dissolved inorganic carbon, $\mathrm{DIC}$ ), and $\mathrm{pH}$. The saturation state of siderite can

94 be expressed with the following relation:

$$
\mathrm{FeCO}_{3}(\text { siderite })=\mathrm{Fe}^{2+}+\mathrm{CO}_{3}^{2-}
$$

96 At solubility equilibrium:

$$
\mathrm{K}_{\mathrm{sp}}=a_{\mathrm{Fe} 2+}{ }^{*} a_{\mathrm{co} 2-}=10^{-10.24} \text { (Fosbøl et al., 2010) }
$$

98 Under non-equilibrium conditions the ion activity product (IAP) and siderite saturation (SI) are:

$$
\mathrm{IAP}=\mathrm{a}_{\mathrm{Fe} 2+}{ }^{*} \mathrm{acO}_{\mathrm{CO}}{ }^{-}
$$

$$
\Omega=\mathrm{IAP} / \mathrm{Ksp}
$$

$$
\mathrm{SI}=\log _{10}(\Omega)
$$

Recent studies of the $\mathrm{Fe}(\mathrm{II})$-carbonate system at ambient temperature (Dideriksen et al.,

103 2015; Jiang and Tosca, 2019) have shown that homogeneous nucleation of Fe(II)-carbonate 104 commonly involves the initial formation of a precursor phase (i.e., amorphous Fe carbonate or AFC) 105 and that its apparent solubility corresponds approximately equal to an $\mathrm{SI}=2.6$. Thus, we adopt an 106 operational definition for the threshold associated with homogeneous nucleation at this saturation state (Steefel and Van Cappellen, 1990; Van Cappellen, 1991). The conditions dominated by 
108 siderite growth (in the presence of seed material) should therefore lie within a range of $\mathrm{SI}=0$ to 2.6

109 (Dideriksen et al., 2015), while at Sl>2.6, the homogeneous nucleation process is expected to 110 dominate.

Precipitation experiments were conducted in $500 \mathrm{ml}$ glass and LDPE bottles, covered in

112 aluminium foil to prevent UV photolysis. The bottles were sealed with no headspace in order to 113 achieve a closed system (and to prevent $\mathrm{CO}_{2}$ degassing). All experiments were conducted in an 114 anoxic glovebox, with $96 \% \mathrm{~N}_{2}$ and $4 \% \mathrm{H}_{2}$ atmosphere. Palladium catalysts and anhydrous $\mathrm{CaSO}_{4}$ 115 desiccant ensured the oxygen concentration within the glovebox remained less than $1 \mathrm{ppm}$, and the 116 ambient atmosphere was kept at low relative humidity. All reactant stock solutions were prepared in 117 the anoxic glovebox using $18 \mathrm{M}-\Omega$ deionized (DI) water. The water was purged with $\mathrm{O}_{2}$ free- $\mathrm{N}_{2}$ gas 118 for 1 hour (Butler et al., 1994) and then left on a stir plate for 30 minutes in the glovebox to allow for 119 the removal of residual oxygen.

Stock solutions prepared beforehand included $1 \mathrm{M} \mathrm{NaCl}$ and $1 \mathrm{M} \mathrm{NaOH}$. 3- $(N-$ morpholino)propanesulfonic acid (MOPS) and $\mathrm{NaOH}$ were together used to control the $\mathrm{pH}$, while

$122 \mathrm{NaCl}$ was used to produce a range of salinities and ionic strengths, approaching values corresponding to natural settings from fresh to marine pore waters. Because MOPS features significant steric hindrance of its acid-base functional groups, it does not exhibit appreciable complexation with transition metals such as $\mathrm{Fe}^{2+}$ in solution (Kandegedara and Rorabacher, 1999).

126 After initial preparation (with $\mathrm{FeCl}_{2}$ ), the $1 \mathrm{M} \mathrm{Fe}^{2+}$ stock solution was treated with $\mathrm{Fe}^{0}$ powder (>99\%, 127 Sigma-Aldrich) and $\mathrm{HCl}(1 \mathrm{M})$ to reach a $\mathrm{pH}$ of 2, and left for 24 hours. This treatment reduced any $128 \mathrm{Fe}^{3+}$ in solution introduced from the reagent powder or from residual oxygen, and stabilised the 129 solution. After 24 hours, the solution was passed through a container with a Nd-magnet embedded 130 in the bottom to remove the $\mathrm{Fe}^{0}$ from solution. $1 \mathrm{M} \mathrm{NaHCO}_{3}$ solution, used to supply the carbonate in 131 the reaction, was freshly prepared before each experiment to limit degassing.

132 Nucleation experiments were conducted at $20^{\circ} \mathrm{C}$ (i.e., ambient temperature) and were started upon 133 the delivery of $\mathrm{NaHCO}_{3}$ stock solution with a syringe before being sealed with an opaque bottle cap. 134 After delivery of the Fe stock solution, the experiments were left to run for 24 hours on an orbital 
135 shaker. The resulting precipitate was vacuum filtered in the glovebox and allowed to dry for 48

136 hours within the glovebox (covered in foil to avoid photo oxidation). The $\mathrm{pH}$ of each experiment was

137 measured at the start (after addition of $\mathrm{Fe}^{2+}$ ) and at the end (before filtration of precipitate). For

138 growth experiments, the procedure was the same as stated above, except a premade pure (verified

139 by X-ray diffraction) siderite seed was added to facilitate growth. The siderite seed (Supplementary

140 Information) was imaged using FEI FEG Scanning Electron Microscope (SEM) at the Department of

141 Earth Sciences, University of Oxford and the specific surface area was found to be $6 \mathrm{~m}^{2} / \mathrm{g}$ as

142 analysed using BET surface analysis (Micromeritics 3flex) at the Chemistry Research Laboratory,

143 University of Oxford. Growth experiments were left for 25-30 days without stirring but were

144 periodically shaken. Two elevated temperature growth experiments were also conducted at $40^{\circ} \mathrm{C}$

145 and $55^{\circ} \mathrm{C}$ respectively, under the same conditions. In these two cases, a stir plate with an integrated

146 hotplate and temperature probe was used. The temperature probe was placed in the solution

147 through the sealed septum placed in the bottle cap.

148 The conditions explored within these experiments are summarised in Table 1. Fe concentration was

149 kept constant within batches of experiments, while $\mathrm{Ca}, \mathrm{Mn}$, and $\mathrm{Mg}$ were varied with reference to

150 Fe. The Fe concentration was chosen based on reported pore waters from modern bogs (Postma,

151 1980; Pye et al., 1990), which vary from $0.2-1 \mathrm{mmol} / \mathrm{kg}$ with depth. It was necessary to conduct

152 experiments at a higher concentration of Fe than reported from natural waters to produce enough

153 solid precipitate for a range of analyses, and so that time-resolved changes in aqueous

154 concentration could be observed with relatively high precision. The saturation states of our growth

155 experiments are lower than previous experimental studies (Romanek et al., 2009; Thornber and

156 Nickel, 1976).

\begin{tabular}{llll}
\hline & Nucleation & Growth & High Temperature \\
\hline Cation concentrations & Fe, Mn, Ca: $1-10$ & Fe, Mn, Ca: $0.1-$ & Fe: $1 \mathrm{mmol} / \mathrm{kg}$ \\
& $\mathrm{mmol} / \mathrm{kg}$ & $1 \mathrm{mmol} / \mathrm{kg}$ & $\mathrm{Mg}: 0.5 \mathrm{mmol} / \mathrm{kg}$ \\
& $\mathrm{Mg}: 0.25-52$ & $\mathrm{Mg}: 0.05-5$ & \\
& $\mathrm{mmol} / \mathrm{kg}$ & $\mathrm{mmol} / \mathrm{kg}$ & \\
DIC- & $10 \mathrm{mmol} / \mathrm{kg}$ & $2-5 \mathrm{mmol} / \mathrm{kg}$ & $5 \mathrm{mmol} / \mathrm{kg}$
\end{tabular}




\begin{tabular}{llll}
$\mathbf{p H}$ & $7-9$ & $7-8$ & 7.5 \\
lonic Strength & $0.013-0.7$ & $0.013-0.106$ & 0.013 \\
$\log \Omega$ & $2-3.6$ & $0.5-1.975$ & $2.38-2.65$ \\
Stirring & Orbital shaker & No & $\begin{array}{l}\text { Hot plate with integrated } \\
\text { stir plate }\end{array}$ \\
Siderite seed & No & Yes & Yes \\
Temperature & $25^{\circ} \mathrm{C}$ & $25^{\circ} \mathrm{C}$ & $40^{\circ} \mathrm{C}$ and $55^{\circ} \mathrm{C}$ \\
\hline \multicolumn{4}{r}{} \\
\end{tabular}

Solution samples were taken at the beginning and end of the nucleation experiments, and

159 every 2-4 days during growth experiments (depending on the length of the experiment). The

160 solution samples were immediately acidified with $5 \% \mathrm{HNO}_{3}$ and analysed for major element

161 chemistry using Inductively Coupled Plasma-Optical Emission Spectrometry (ICP-OES) at Scottish

162 Universities Environmental Research Centre (SUERC) and Department of Earth Sciences, UCL. All

163 analysis batches included matrix matched quality control standards. Rates of reactions were

164 calculated by the difference in measured cation concentration ( $\mathrm{Fe}$ and $\mathrm{Mn})$ over a given time unit,

165 and correcting the saturation state by subtracting DIC and recalculating for the next time step.

166 Precipitates were analysed using a FEI FEG-SEM at Oxford to image the crystalline morphology at

167 high resolution. An EDS detector was used to constrain elemental composition of experimental

168 precipitates. The precipitates were also analysed using a PANalytical Empyrean Series 2 X-ray

169 diffractometer at Oxford, which used a Co Ka source at $40 \mathrm{kV}$ and $40 \mathrm{~mA}$. Samples were prepared

170 in the glovebox on zero-background single crystal silicon substrates and sealed with X-ray

171 transparent Kapton film prior to analysis.

\section{$172 \quad 4 \quad$ Results}

$173 \quad 4.1 \quad \mathrm{Fe}(\mathrm{II})$-carbonate precipitation pathways

After removal of Al foil, precipitates were visibly identified in nearly all experiments. Once

75 filtered, the precipitates ranged in colour from greenish-gray to dark brown, as is typical of $\mathrm{FeCO}_{3}$ 
176 synthesis (Fosbol et al., 2010). The precipitates were dried at $25^{\circ} \mathrm{C}$ and also changed colour when

177 drying, generally becoming darker. Powder X-Ray diffraction analyses confirmed that experimental

178 precipitates were dominated by Fe(II)-carbonate minerals (Supplementary Information). XRD

179 analysis of precipitates formed between $\mathrm{pH} 7$ and 8 show the material to be mostly siderite.

180 Exceptions to this included some of the higher $\mathrm{pH}$ experiments ( $\mathrm{pH} 8$ to 9 ) which also produced

181 chukanovite $\left(\mathrm{Fe}_{2}(\mathrm{OH})_{2} \mathrm{CO}_{3}\right)$. Precipitate morphology varied from siderite rhombohedra of various

182 forms ( 1-4 $\mu \mathrm{m}$ in length) to spherical particles composed of clusters of smaller rhombs (Fig 1). The 183 spheres were on average $10 \mu \mathrm{m}$ in diameter, while the constituent rhombs comprising the spheres 184 were typically $<1 \mu \mathrm{m}$ along single crystal edges.
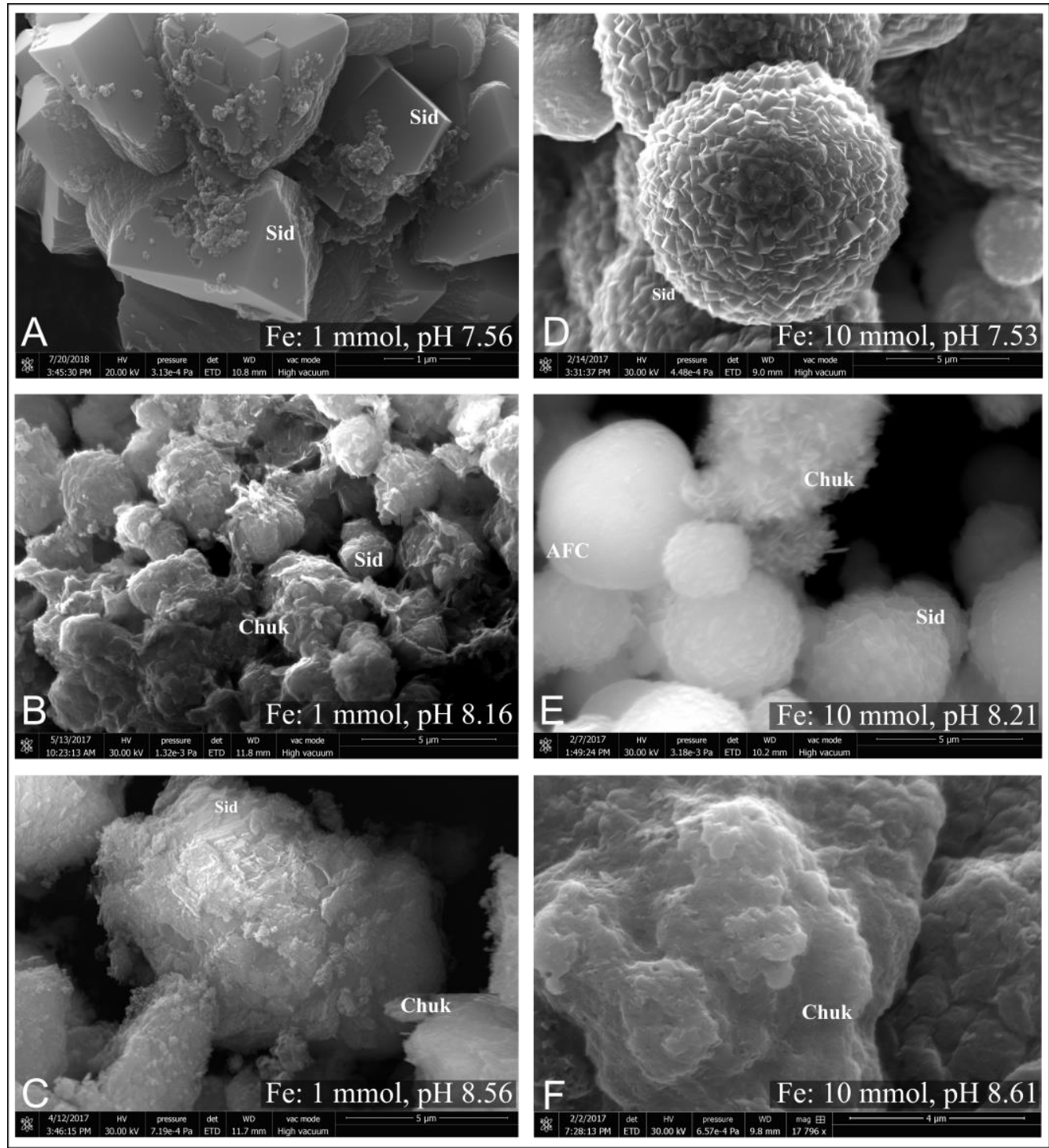
Figure 1: SEM micrographs of experimental precipitates showing representative morphological endmembers. A to C) Fe concentration $1 \mathrm{mmol} / \mathrm{kg}$, $D$ to F) Fe concentration $10 \mathrm{mmol} / \mathrm{kg}$. Morphological diversity is attributed to the range of siderite saturation states investigated, which in turn controls the rates of nucleation and growth. As shown from $A$ to $C$ and $D$ to $F$, increasing $p H$ causes precipitates to change from pure siderite to a mixture of siderite and chukanovite, to pure chukanovite. E shows a spherical particle with no apparent crystalline morphology at the resolution limit of the SEM (10s of $n m$ ), and is interpreted to be amorphous iron carbonate (AFC), which recrystallized to form the spherical clusters of rhombs, similar to polycrystalline particles shown in $D$.

\footnotetext{
Above $\mathrm{pH}$ 8, pure siderite could not be obtained. The precipitate was either a mixture of siderite and chukanovite or purely chukanovite. Between $\mathrm{pH} 8.5$ and 9 the precipitates were nanocrystalline and often purely chukanovite (Fig 1c, f). Chukanovite $\left[\mathrm{Fe}_{2}\left(\mathrm{CO}_{3}\right)(\mathrm{OH})_{2}\right]$ is an iron(II) carbonate hydroxide with acicular, platy or fibrous crystals. It is metastable with respect to siderite, and thus can transform to siderite with time (Azoulay et al., 2012). The presence of chukanovite and siderite mixed within the sample (Fig 1b, e) indicates more than one formation pathway for siderite, probably through competitive surface nucleation of the two phases on an amorphous precursor (Dideriksen et al., 2015).
}

The range in morphology (rhombs to spherical clusters of rhombs) is most likely influenced by the balance between nucleation and growth rates. Previous studies of $\mathrm{Fe}(\mathrm{II})$-carbonate precursor structures and stability have shown that the amorphous precursor provides a low energy pathway to Fe(II)-carbonate mineralisation (Sel et al., 2012; Dideriksen et al., 2015). After its initial nucleation, the amorphous precursor provides a substrate for the subsequent heterogeneous nucleation of siderite (or chukanovite), as observed in other mineral systems (Van Cappellan, 1992; Nielsen et al., 2014). Rapid surface nucleation would therefore replace the initially spherical amorphous particle with a significant number of siderite rhombs encrusted on its surface (Van Cappellan, 1992; Nielsen et al., 2014). This process continues until the amorphous precursor is consumed and progressively replaced by siderite, yielding an overall morphology that Dideriksen et al. (2015) 
214 argued was a distinctive product of this mineralisation pathway. This morphology is identical to that 215 observed in our experiments (Fig 1d, e). The clusters of rhombs in spherical polycrystalline 216 aggregates were primarily noted in our nucleation experiments with $\mathrm{Fe}^{2+}$ concentration of $10 \mathrm{mmol}$, 217 allowing a high saturation state and rapid nucleation. The rhombohedral crystal shape was 218 observed in experiments with lower $\mathrm{Fe}^{2+}$ concentration of $1 \mathrm{mmol}$ as well as lower $\mathrm{pH}$, and therefore 219 lower saturation, together promoting slower nucleation rates relative to growth rates.

\section{$221 \quad 4.2 \quad$ Cation uptake in siderite}

\section{$222 \quad$ 4.2.1 Mn uptake}

Mn uptake was observed in all experiments with $\mathrm{Mn}^{2+}$ present in the initial solution (a range 224 of such data from growth experiments is presented in Fig 2). Fe and Mn decreased in all growth 225 experiments with time (Fig 2). In experiment 8 at pH 8 (Fig 2), Fe and Mn show a slight increase 226 after 20 days; this pattern is observed across all cations analysed. As solution samples were 227 analysed in groups and retained in the glovebox after acidification, we interpret this to reflect 228 gradual sample evaporation in the low-humidity glovebox atmosphere with increased experiment 229 duration. During growth experiments Fe/Mn ratios increased as reactions progressed, coincident 230 with decreasing siderite saturation, which in turn led to decreasing growth rates. Because 231 experiments were conducted in closed vessels, the removal of Fe during precipitation leads to a 232 progressive decrease in siderite saturation state and therefore lower reaction rates with time. The 233 negative relationship between rate and Fe/Mn indicates (data not shown) that $\mathrm{Mn}$ uptake is 234 influenced by the siderite saturation state in solution. 

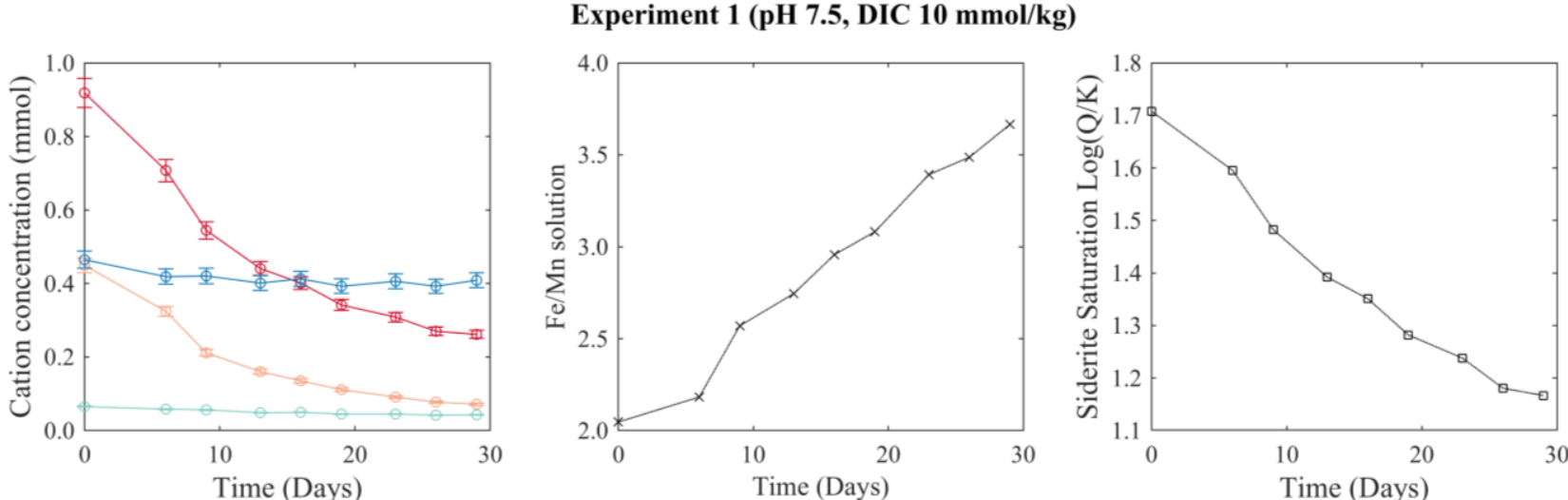

Experiment 6 (pH 7.5, DIC $5 \mathrm{mmol} / \mathrm{kg}$ )
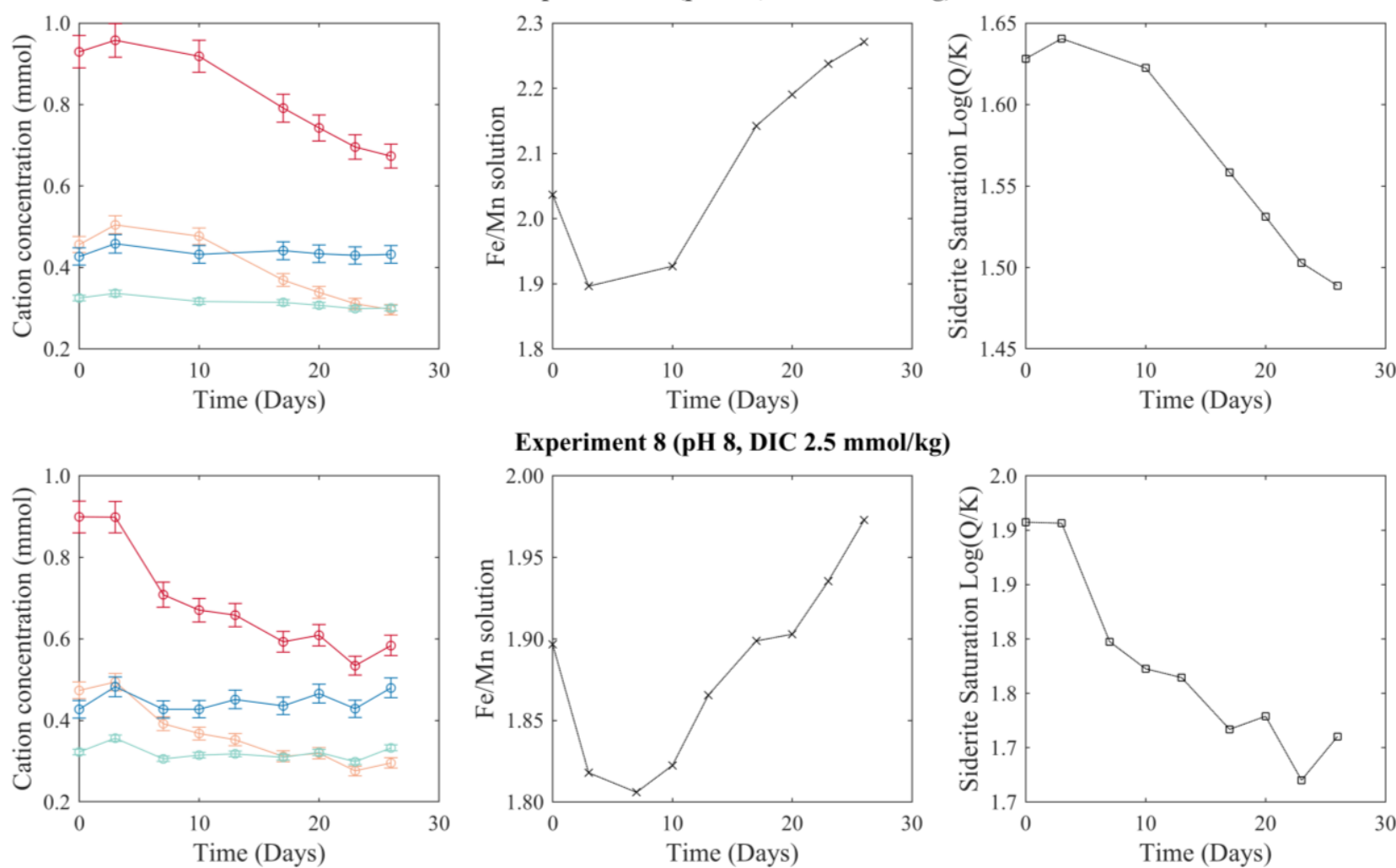

Experiment 8 (pH 8, DIC $2.5 \mathrm{mmol} / \mathrm{kg})$
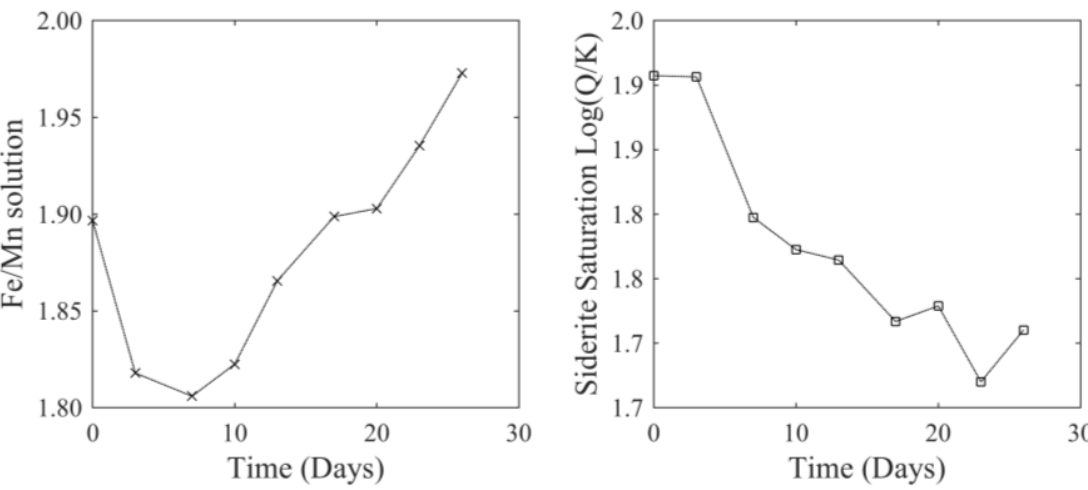

236 Figure 2: Selection of growth experiments displaying cation concentration in solution with time. Pure

237 siderite seed $(0.5 \mathrm{~g})$ was added at the start of all experiments. Fe and Mn uptake are notable. The

238 differences in $\mathrm{Fe}$ uptake reflect differences in starting $\mathrm{pH}$ and $\mathrm{pCO}_{2}$, and therefore saturation state,

239 between the experiments. Fe/Mn of the solution increases with decreasing siderite saturation,

240 indicating that $\mathrm{Mn}$ is incorporated into the precipitate in preference to Fe with decreasing reaction

241 rate of siderite. Ca and $\mathrm{Mg}$ concentrations are generally invariable, and uptake is not discernible.

242 The final concentrations of $\mathrm{Ca}$ and $\mathrm{Mg}$ in all experiments are within error of the initial concentration. 
$\mathrm{Fe} / \mathrm{Mn}$ ratios of the initial solution and the final precipitate show a strong positive correlation

244 for both nucleation and growth experiments as shown in Fig 3, but the evolution of Fe/Mn in solution

245 over time (Fig 2) suggests cation ratios are not the sole factor in controlling Mn uptake. The

246 correlation between Fe/Mn of the precipitate and initial solution appears to deviate from a 1:1 line

247 (Fig 3), although this deviation is statistically insignificant. The relationship between calculated

$248 \mathrm{Fe} / \mathrm{Mn}$ in the precipitate and the initial $\mathrm{Fe} / \mathrm{Mn}$ in nucleation experiments also varies with crystalline

$249 \mathrm{Fe}(\mathrm{II})$-carbonate phase (siderite and chukanovite). EDS spectra and ICP-OES data from pure

250 chukanovite samples (Fig 3) shows Mn uptake in chukanovite to be less than in siderite. However, a 251 positive correlation is still present, regardless of the phase, as evidenced by a similar trend in the 252 pure siderite growth experiments.
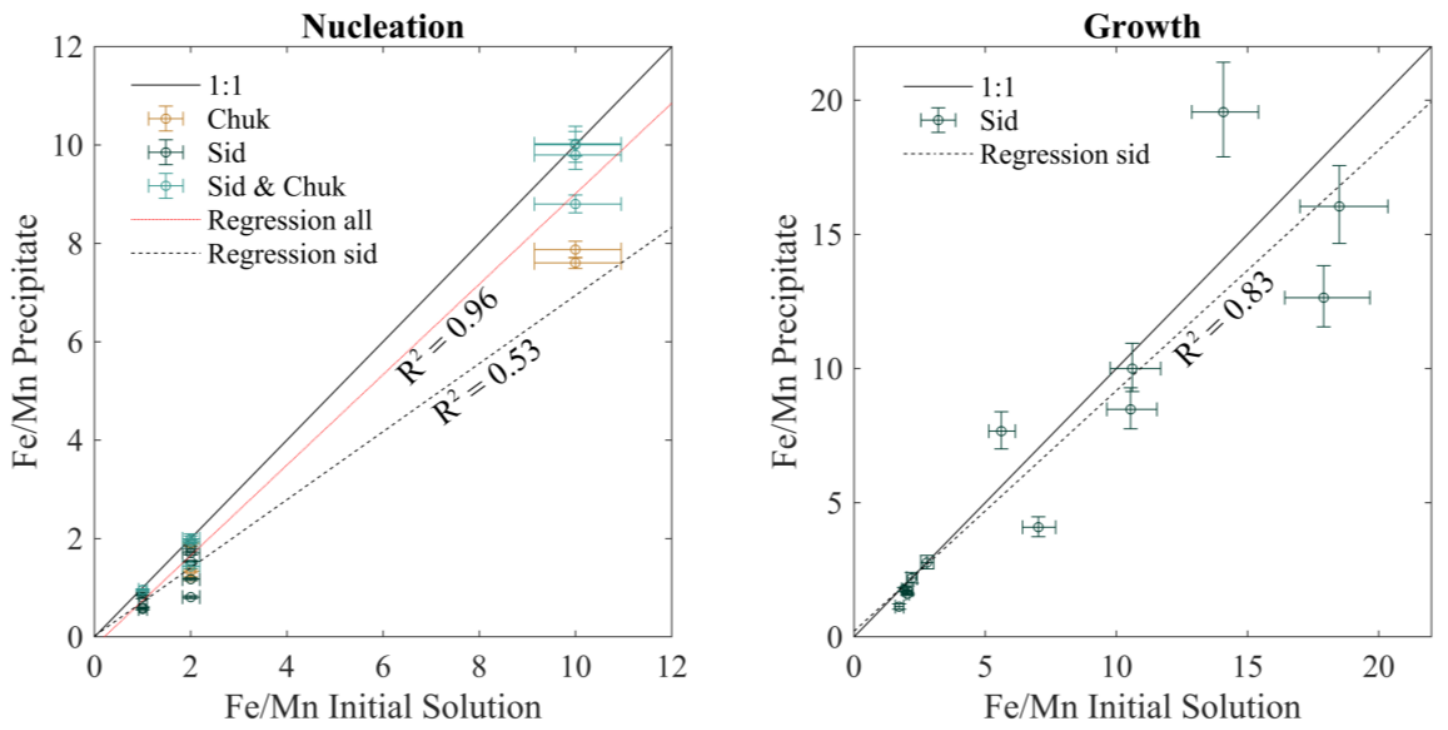

254 Figure 3: Fe/Mn of precipitate and initial solution in growth and nucleation experiments. Fe/Mn of final precipitate was calculated from the initial and final Fe/Mn ratios from solutions.

\subsubsection{Ca uptake in siderite}

For nucleation experiments, Ca was incorporated into siderite with less preference than for

258 Mn. Ca uptake was between $10-30 \%$ of initial concentration in nucleation experiments, but

259 correlations with factors such as $\mathrm{pH}$, cation concentrations or $\mathrm{pCO}_{2}$ were not statistically

260 meaningful. At higher $\mathrm{pH}, \mathrm{Ca}$ uptake appeared to increase, but the presence of multiple phases 
262 Information).

In contrast, during growth experiments, Ca uptake was not discernible when $\mathrm{Mn}$ was present (Fig 2). Although there is some variation in Ca over time, mostly noticeable in experiment 8 (Fig 2), this is likely an artefact of dilution. The final concentration of $\mathrm{Ca}$ is still within error of the starting concentration, and therefore Ca uptake is not discernible using ICP-OES. EDS spectra of some of the growth experiments show a very minor amount of Ca present in the precipitate (0.5- 1.6 Wt \%). The amount detected also increased when the average rate of the experiment was generally higher. For instance, one experiment with an average rate of growth of $0.02 \mathrm{mmol} /$ day showed $1-1.2$ wt \% uptake of Ca on EDS. In contrast, an experiment with a rate of a growth of $0.002 \mathrm{mmol} / \mathrm{day}$, resulted in an EDS measurement of 0.2-0.6 wt \% Ca. However, these quantities are very close to the detection limits of SEM-EDS and cannot be used for quantitative analyses. They are presented simply to support the solution chemistry data which suggests that $\mathrm{Ca}$ uptake was negligible during growth experiments.

Control growth experiments at low saturations were conducted with only $\mathrm{Fe}$ and $\mathrm{Ca}$ to investigate whether the presence of Mn was inhibiting Ca uptake. In these experiments there is no observable uptake of $\mathrm{Ca}$ under the conditions explored here, despite clear evidence for siderite growth (Fig 4). EDS spectra yielded 0.2-0.5 Wt\% Ca in these control experiments.
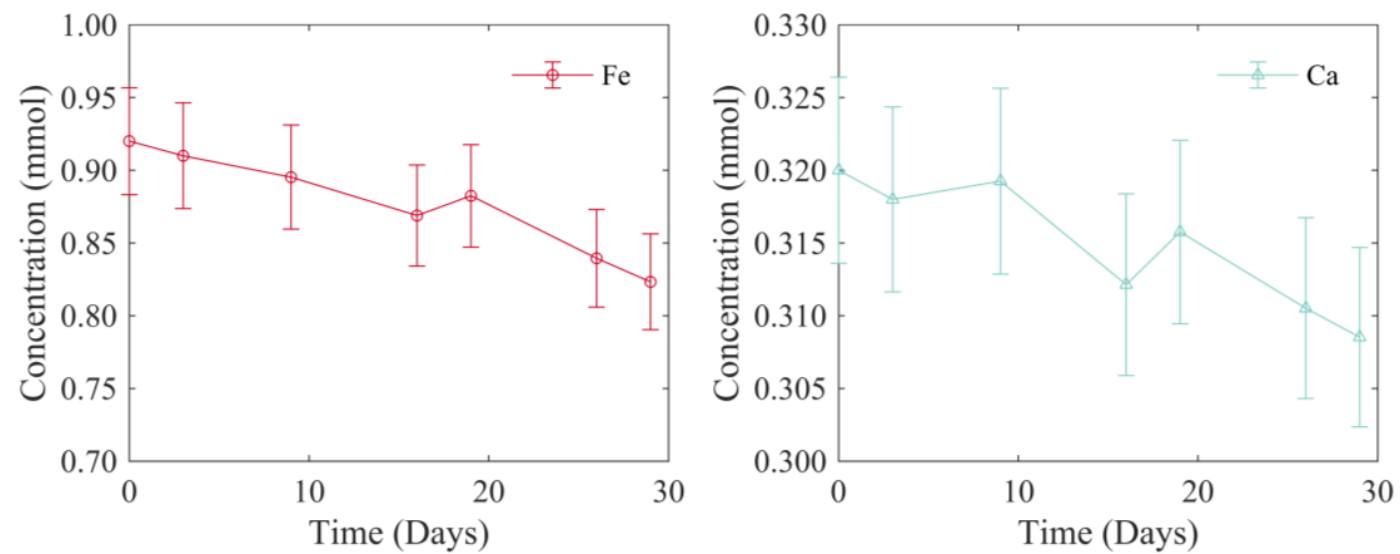

Figure 4: Control growth experiments with only Fe and $\mathrm{Ca}$ in starting solution showed decrease in Ca, but within error. Therefore no discernible uptake can be noted from the control experiments. 


\subsubsection{Mg uptake in siderite}

ICP-OES data show no evidence for Mg uptake into siderite in either nucleation or growth experiments at ambient temperature. Some variation in Mg concentration is noted in Fig 2, although this is mainly in Experiment 8. Similar to the Ca concentrations discussed above, the variations in Mg can be attributed here to inconsistencies in dilution between some samples. However, the end concentration and the starting concentration of $\mathrm{Mg}$ are within error of each other and therefore significant Mg uptake is not detectable by ICP-OES.

As mentioned previously, nucleation experiments above $\mathrm{pH} 8$ produced a mixture of siderite and chukanovite. EDS-SEM point analysis on these samples detected a small Mg peak, although it was very close to the detection limit. As this peak was noted in $60 \%$ of samples above $\mathrm{pH} 8$, it could be inferred that a very minor amount of Mg may have been taken up in the chukanovite structure, but not enough to be detectable by ICP-OES. This was the case irrespective of whether Mn and/or Ca were present in solution, including at modern marine concentrations of $\mathrm{Mg}(52 \mathrm{mmol}) . \mathrm{Mg}$ is known to inhibit calcite growth at seawater concentrations (Zhang and Dawe, 2000; Davis et al., 2004; Chen et al., 2005) but, in contrast, Mg did not appear to have any effect on Mn or Ca uptake in siderite in the experimental temperature and pressure ranges used, even at modern seawater concentrations.

As previous studies have considered the effect of temperature on Mg uptake in siderite (Romanek et al., 2009), two higher temperature Mg control experiments were also conducted to explore this effect further. As expected, the rate of seeded siderite growth increases with temperature (Fig 5). The $40^{\circ} \mathrm{C}$ experiment yielded no evidence for $\mathrm{Mg}$ uptake, within analytical error. At $55^{\circ} \mathrm{C}, \mathrm{Mg}$ uptake was statistically significant, though minor, at $0.0099 \mathrm{mmol}$ in total $(<2 \mathrm{~mol} \%$ uptake). SEM-EDS point analysis detected a small Mg peak, although it is bordering on the detection limit. 

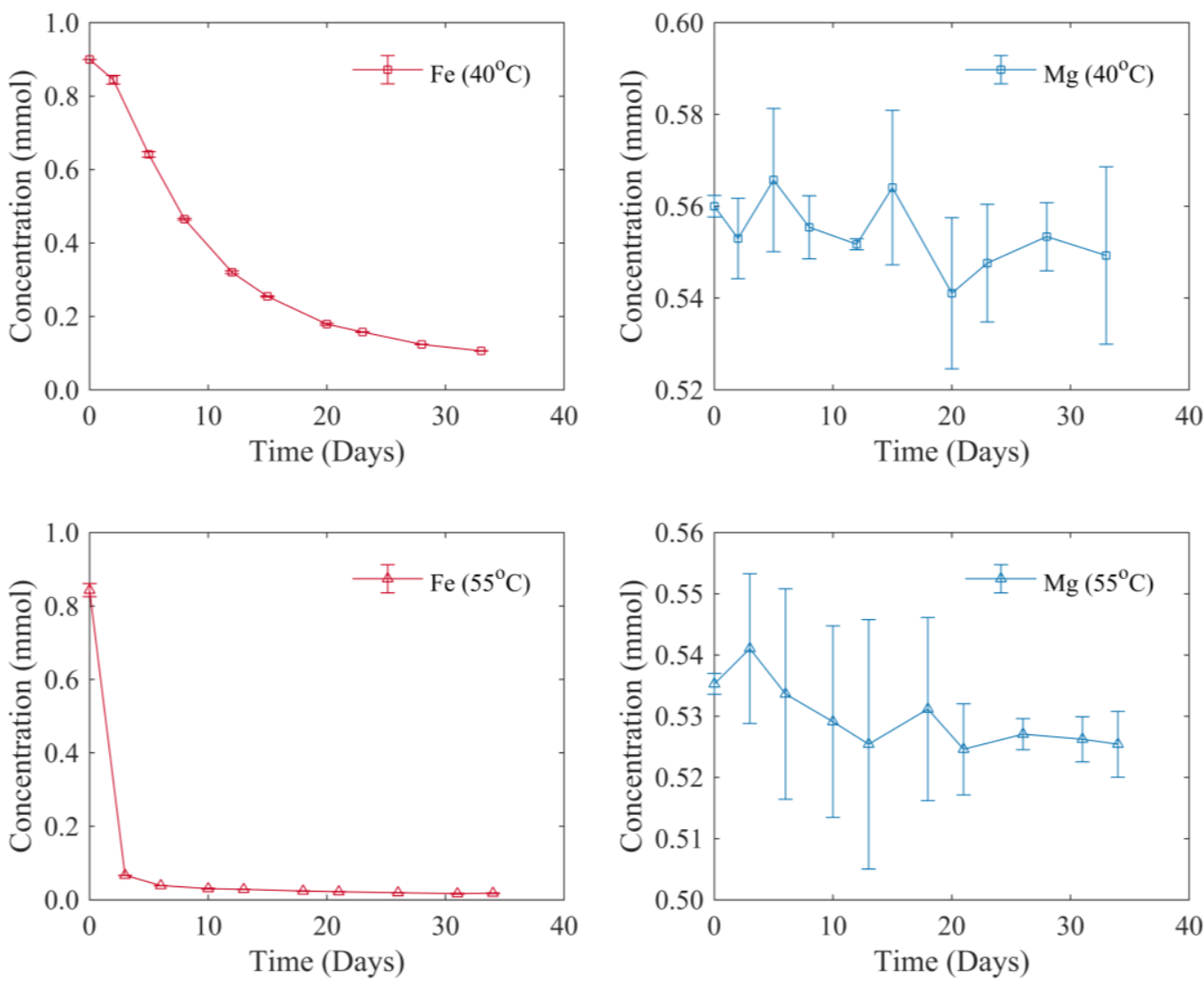

Figure 5: Control experiments with $\mathrm{Fe}$ and $\mathrm{Mg}$ as the only available cations to monitor $\mathrm{Mg}$ uptake in siderite at elevated temperatures, and in the absence of competing cations. Mg uptake was only discernible at $55^{\circ} \mathrm{C}$.

\subsection{Rates of growth}

Solution chemistry data from seeded growth experiments indicate that each experiment is associated with significant Mn uptake, in addition to Fe, into overgrowths precipitated on siderite

314 seed material. Thus, in order to calculate growth rates as a function of solution supersaturation, we chose to evaluate supersaturation with respect to a Mn-bearing siderite with a composition equating to the average $\mathrm{Mn}$ coprecipitated in overgrowths (i.e., $11 \mathrm{~mol} \% \mathrm{Mn}$ in $\mathrm{FeCO}_{3}$, or $\mathrm{Fe}_{0.89} \mathrm{Mn}_{0.11} \mathrm{CO}_{3}$ ). In order to estimate the $\log \mathrm{K}_{\mathrm{sp}}$ for such a material, we assumed a complete binary solid solution between $\mathrm{MnCO}_{3}$ and $\mathrm{FeCO}_{3}$ and employed a regular solid solution model to estimate activity coefficients of solid phases (Glynn, 2000). This regular solid solution model employs the

320 dimensionless parameter, ao, which is used in the expansion series to estimate the excess Gibbs free energy of mixing between two end-members (Glynn, 2000). For the (Fe,Mn) $\mathrm{CO}_{3}$ system, this 
322 dimensionless parameter is constrained to a value $<2.0$ based on experimental data (Glynn, 2000).

323 We used a log $\mathrm{K}_{\mathrm{sp}}$ value for $\mathrm{FeCO}_{3}$ equal to -10.24 (Fosbøl et al., 2010) and, for $\mathrm{MnCO}_{3}$, a log $\mathrm{K}_{\mathrm{sp}}$ 324 value equal to -12.51 (Jensen et al., 2002). The resulting $\mathrm{K}_{\mathrm{sp}}$ for $(\mathrm{Fe}, \mathrm{Mn}) \mathrm{CO}_{3}$ as a function of 325 composition is illustrated in Fig 6.

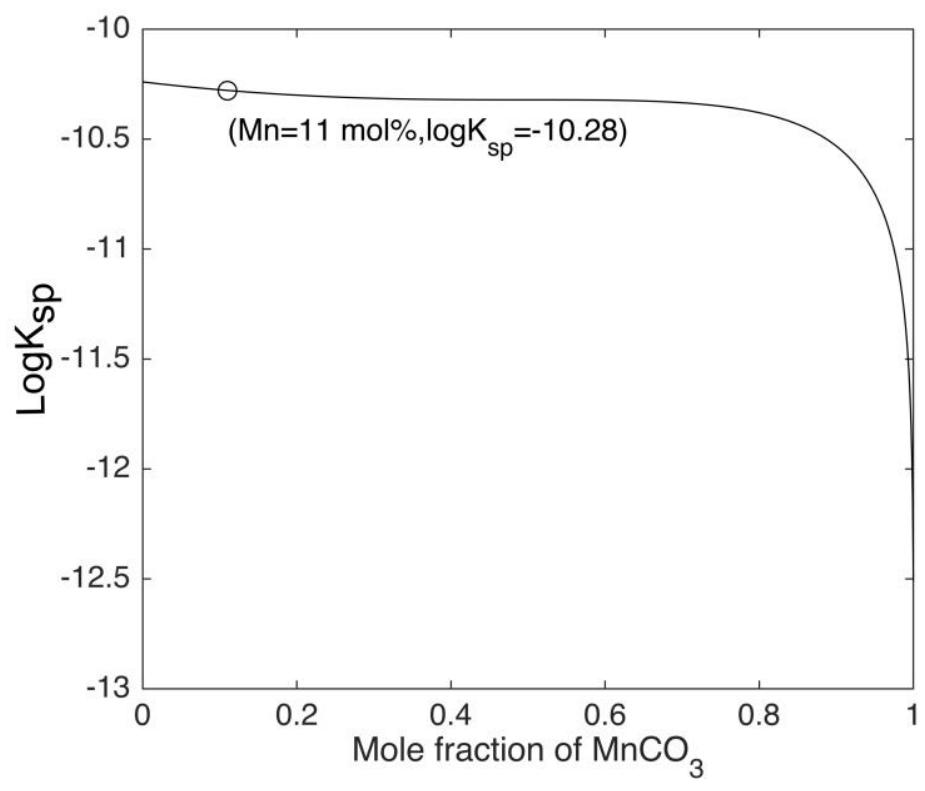

327 Fig 6: Calculated $K_{s p}=-10.28$ at Mn substitution of 11 mol\% into the carbonate phase formed on 328 average during seeded growth experiments.

Experimentally calculated surface area-normalised growth rates for seeded experiments are shown in Fig 7 as a function of supersaturation relative to $\mathrm{Fe}_{0.89} \mathrm{Mn}_{0.11} \mathrm{CO}_{3}$. Although the data are highly scattered, a statistically significant relationship between growth rate and precipitation is 332 evident within the $95 \%$ confidence interval. This relationship can be expressed with a general rate 333 law for growth:

$$
R=k(\Omega-1)^{n}
$$
where $\mathrm{R}$ is rate ( $\mathrm{mol} / \mathrm{m}^{2} /$ hour) $\mathrm{k}$ is the rate constant, $\mathrm{n}$ is the empirical reaction order and $(\Omega$ -

336 1) is the supersaturation with respect to $\mathrm{Fe}_{0.89} \mathrm{Mn}_{0.11} \mathrm{CO}_{3}$. Our data constrain $\mathrm{n}$ to 0.95 and $\mathrm{k}$ to $3378.11 \mathrm{E}-8 \mathrm{~mol} / \mathrm{hr}$. The empirical reaction order is generally thought to contain information about the 338 dominant growth mechanism (Teng et al., 2000). Kinetic studies of mineral growth typically attribute 
$\mathrm{n}$ values of 1 to reflect adsorption-controlled growth, values of 2 to reflect growth at screw

340 dislocations via a spiral growth mechanism, and values $>2$ to reflect growth at screw and edge

341 dislocations (Teng et al., 2000). However, this general rate law does not take into account the

342 structure and source of dislocations at the mineral surface and, because such empirical rate laws

343 are typically derived from bulk solution chemistry measurements, do not reflect growth processes

344 actually operating at mineral surfaces (Teng et al., 2000). From our experimental data we are

345 unable to resolve statistically significant crossover points in the empirical reaction order as a

346 function of supersaturation which might be taken to reflect a change in the dominant mechanism.

347 More data will be required to elucidate this dependence, in particular direct observations of the 348 dominant surface growth mechanism under these conditions.

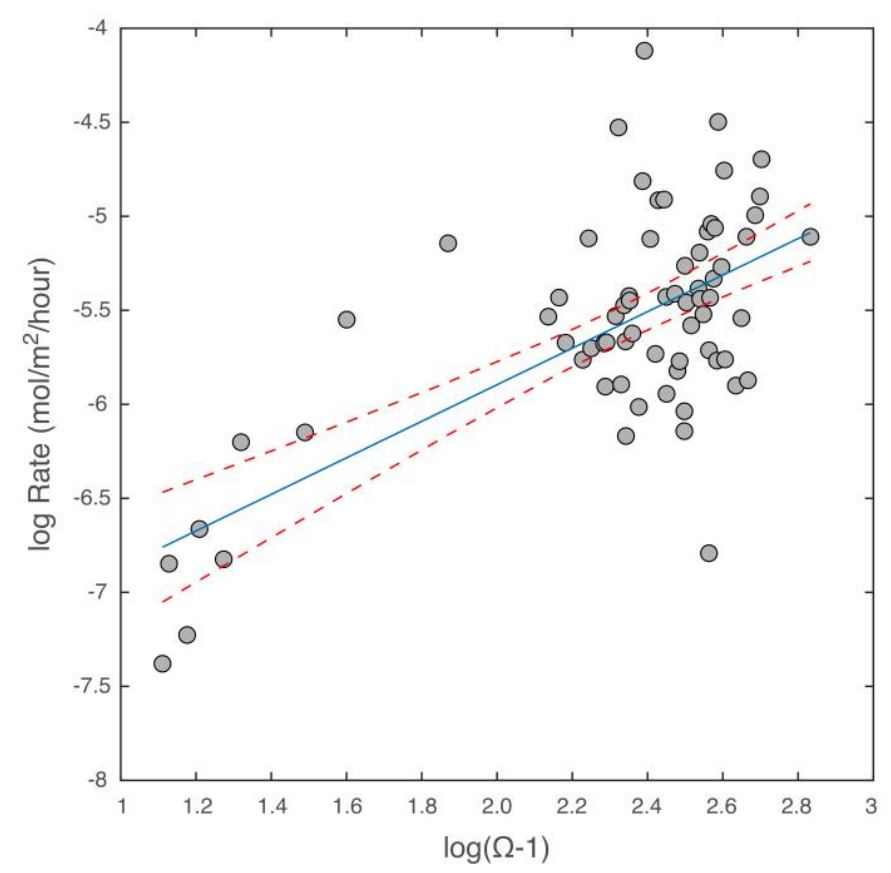

350 Figure 7: Experimental rates $\left(\mathrm{mol} / / \mathrm{m}^{2} / \mathrm{hr}\right)$ from seeded growth experiments. Dashed lines indicate $35195 \%$ confidence intervals.

\section{$352 \quad 4.4$ Effect of salinity changes}

353 As mentioned in Table 1, salinity changes were explored using $\mathrm{NaCl}$ concentrations analogous to 354 fresh, brackish and marine waters, in the presence of $\mathrm{Fe}, \mathrm{Mg}, \mathrm{Ca}$ and $\mathrm{Mn}$ as available cations. 
355 However, salinity changes were found to have no significant effect on the uptake behaviours

356 described in the above sections (Supplementary Information).

\section{Discussion}

\section{$358 \quad 5.1 \quad$ Comparison to previous studies}

$359 \quad$ 5.1.1 Trace element uptake in siderite

In their examination of the partitioning of trace elements between carbonate minerals and

361 aqueous solutions, Rimstidt et al. (1998) observed that, for calcite, the apparent distribution

362 coefficients derived from experimental work correlated with the quotient of the solubility product of

363 the host carbonate to the trace element carbonate. The authors also extended this analysis to

364 siderite, using an experimental dataset reported previously (Thornber and Nickel, 1976). To

365 facilitate comparison to our experimental data, we have also estimated apparent trace element

366 distribution coefficients for siderite from Romanek et al. (2009), plotted in Fig 8.

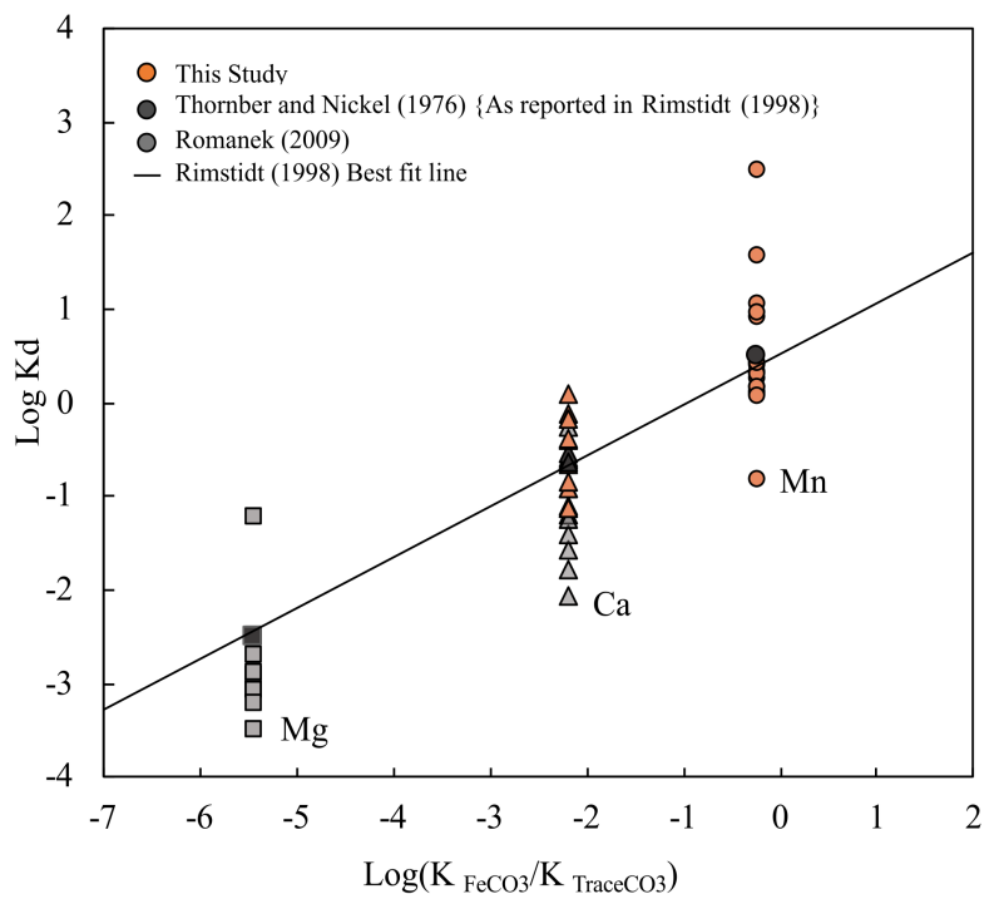

368 Figure 8: Comparisons of apparent distribution coefficients (Kd') from Romanek et al (2009),

369 Rimstidt et al (1998) and calculated Log K (Rimstidt et al., 1998). Kd is positively correlated to the 
solubility quotient of siderite with respect to trace cation, displaying a clear preference of Mn uptake over Ca and Mg.

Our data support the initial observation by Rimstidt et al. (1998) that, in addition to calcite, trace element incorporation into siderite correlates with the quotient of the siderite and trace element carbonate solubility products. Although available experimental data show significant variation about this trend, this general correlation leads to two conclusions. The first is that, as our experiments show, trace element uptake into siderite should occur with increasing preference in the following order: $\mathrm{Mg}<<\mathrm{Ca}<\mathrm{Mn}$; this finding is consistent with Rimstidt et al (1998). Romanek et al. (2009) have previously shown a linear relation between $\mathrm{Ca}: \mathrm{Fe}(\mathrm{aq})$ and $\mathrm{Ca}: \mathrm{Fe}(\mathrm{s})$ in the absence of Mn but presence of $\mathrm{Mg}$. This, along with the low $\mathrm{Kd}$ of $\mathrm{Ca}$ compared to $\mathrm{Mn}$, also implies that $\mathrm{Ca}$ uptake is hindered by the presence of the preferential trace cation Mn.

The second conclusion, noted by Rimstidt et al. (1998), is that the slope of the correlation deviates from the equilibrium slope of 1 , meaning that kinetic processes rather than equilibrium processes ultimately control trace element incorporation into siderite during nucleation and/or growth.

In the discussion that follows, we provide a review of the factors behind these apparent trends in element uptake during siderite growth, and discuss these factors with respect to reported compositional data for ancient siderites.

\subsection{Mechanisms of cation uptake in siderite}

\subsubsection{Cation hydration characteristics}

Free ions (such as $\mathrm{Fe}^{2+}, \mathrm{Mn}^{2+}$ etc.) in aqueous solution are closely associated with $\mathrm{H}_{2} \mathrm{O}$ molecules. Dehydration energies required for a cation to be extracted from these hydrating $\mathrm{H}_{2} \mathrm{O}$ molecules, and become incorporated to a growing crystal surface, are dependent on cation size and charge. Romanek et al. (2009) attributed the lack of Mg uptake during siderite growth at ambient temperature to a higher dehydration energy required for $\mathrm{Mg}^{2+}$ as opposed to $\mathrm{Ca}^{2+}$ and $\mathrm{Fe}^{2+}$. However, the hydration enthalpies of $\mathrm{Mg}^{2+}$ and $\mathrm{Fe}^{2+}$ are, in fact, very similar (Burgess, 1978). Our 
data show that observable Mg uptake does not occur during nucleation or growth at ambient temperatures, regardless of solution chemistry. The presence of $\mathrm{Mg}$ also does not appear to affect the uptake of other cations, where the main trend was a preference for proportional Mn uptake. Finally, if dehydration was a main kinetic control, the relative hydration energies would predict preferential uptake of $\mathrm{Ca}$ over $\mathrm{Mn}$, the opposite to what is observed in our data and in previous studies (Fig 8). Together, this indicates that other factors must be primarily responsible for cation uptake during siderite growth.

\subsubsection{Crystal structure}

The preference for $\mathrm{Mn}^{2+}$ uptake over $\mathrm{Ca}^{2+}$ and $\mathrm{Mg}^{2+}$ during siderite growth could relate partly to structural differences between rhombohedral carbonates. Intuitively, we might expect cations with a similar radius to iron to be accommodated more readily in the siderite structure. Reeder (1983), based on experimental work summarised by Goldsmith (1983), suggested that the differences in ionic radius between cation pairs in rhombohedral carbonates could be divided into two classes: pairs that should exhibit complete miscibility (differences $\leq 0.11 \AA$ ), and those that should exhibit limited miscibility (differences $\geq 0.11 \AA$ ). On this basis, cation radius differences between $\mathrm{Fe}^{2+}$ and $\mathrm{Mn}^{2+}$ and $\mathrm{Fe}^{2+}$ and $\mathrm{Mg}^{2+}$ predict complete miscibility, whereas $\mathrm{Fe}^{2+}$ and $\mathrm{Ca}^{2+}$ predict limited miscibility. To a first approximation, this suggests that there may be few structural barriers to extensive $\mathrm{Mn}$ incorporation in the siderite lattice, consistent with our Mn uptake data. In addition, these relationships suggest that structural factors may limit the amount of $\mathrm{Ca}$ incorporation in the siderite lattice, which may be one factor contributing to the observed low distribution coefficients for Ca. The prediction of full miscibility between $\mathrm{Mg}$ and Fe in siderite, however, suggests that the negligible uptake observed in our experiments and low apparent distribution coefficients (Thornber and Nickel, 1976; Rimstidt et al., 1998; Romanek et al., 2009) may be better explained by kinetic factors. 


\subsubsection{Surface structural control}

Mineral growth mechanisms are strongly controlled by saturation state, implying that the structure of the siderite surface, as it grows in solution, may control trace element uptake. In general, with increasing supersaturation, mineral growth progresses from spiral growth triggered at surface kink sites, to 2D nucleation, and non-classical growth (possibly involving an amorphous precursor) above what is termed the roughening transition (Sunagawa, 2007; Rodriguez-Navarro et al., 2016). However, most natural systems are poised at saturation states that promote spiral growth, which features the advancement of structurally non-equivalent growth steps on growth hillocks (Paquette and Reeder, 1995; Rakovan and Reeder, 1996; Reeder and Rakovan, 1999; Sunagawa, 2007). Previous work on calcite has shown that during spiral growth, trace element uptake is strongly controlled by both the rates of growth step advancement and by structural characteristics of kink sites generated at non-equivalent growth faces (Paquette and Reeder, 1995; Reeder, 1996; Rakovan and Reeder, 1996). This process ultimately results in intra-sectoral zoning of trace elements on the calcite surface (Paquette and Reeder, 1990). This work also suggests that cation size may play a role in determining trace element incorporation at the growing interface, with sterically unconstrained kink sites favouring larger cations and more constricted kink sites favouring smaller cations (Paquette and Reeder, 1995; Rakovan and Reeder, 1996). This work offers a conceptual framework to explain differential element incorporation and variations with growth rate, as we have documented for $\mathrm{Mn}$ incorporation. Specifically, increases in growth rate will translate to increases in the rate of growth step advancement (Gratz et al., 1993). However, different growth steps exposed on symmetrically non-equivalent faces will respond differently to saturation state. On this basis, one explanation for our observed decrease in Mn uptake with increases in growth rates may be that growth rate increases translate to more rapid advancement of growth steps at the siderite surface where Mn incorporation is less favoured, perhaps by surface structural constraints.

Another possibility is that if growth rates of siderite increase to the point where a different growth mechanism begins to dominate (i.e., 2D nucleation), then trace element incorporation may exhibit corresponding differences. However, although the saturation state at which 2D nucleation 
might begin to dominate siderite growth is unconstrained, our growth rate data cannot statistically resolve changes in the empirical reaction order, or the relationship between growth rate and saturation state which might signal a mechanism change.

\subsubsection{Transport / boundary layer control}

An additional kinetic control, discussed by Rimstidt et al. (1998), involves the transport of trace elements through solution to the surface of the growing crystal. Because trace elements are likely to be incorporated at rates that differ from the rate of $\mathrm{Fe}^{2+}$ incorporation into siderite, this may lead to the development of a solution boundary layer that is either depleted in the trace element (i.e., if $\mathrm{Kd}>1$ ) or enriched in the trace element (i.e., if $\mathrm{Kd}<1$ ). This will, in turn, influence the effective Kd, rate of cation diffusion to the growing surface, and/or influence the overall growth rate of the mineral (i.e., lead to oscillatory zoning; Reeder et al., 1990; Wang and Merino, 1992).This relationship predicts that trace elements where the apparent distribution coefficient is $>1$ should exhibit an increase in element uptake with decreasing growth rate. Indeed, our observations of $\mathrm{Mn}$ uptake suggest that this process may be operating, analogous to Mn uptake in calcite (Dromgoole and Walter, 1990). However, as discussed above, because surface structural controls on element uptake may also be important in our system, we cannot uniquely identify which processes are most important. Indeed, both may be operating, leading to a network of complex kinetic controls on element uptake.

The boundary layer is likely to shrink with increasing temperature due to increased rates of diffusion. This would minimise the role of the diffusion layer in controlling cation uptake. However, despite these expectations, available data indicate a number of competing factors as temperature increases. For example, Rimstidt et al. (1998) showed that modelled Kd values for numerous cations in calcite do not change significantly over $0-100^{\circ} \mathrm{C}$ and attributed this to solubility products of carbonates changing similarly with temperature. In their model, however, the $\mathrm{Kd}$ of $\mathrm{Mg}$ in calcite increased with temperature. We return to the influence of temperature on $\mathrm{Mg}$ uptake in siderite in section 5.2.6. 
$474 \quad$ 5.2.5 Non Traditional Precipitation Pathways

As discussed above, there seem to be few structural constraints limiting the extent of $\mathrm{Mg}$ incorporation into the siderite structure, yet $\mathrm{Mg}$ uptake in siderite is characterised by very low distribution coefficients. This is analogous to the incorporation of $\mathrm{Mg}$ in calcite, which is characterised by similarly low distribution coefficients (Reeder, 1983; Rimstidt et al., 1998; Romanek et al, 2009). Yet, Mg-rich calcite is well known from modern and some ancient marine carbonate successions, and notably from biologically-mediated calcite precipitation (Weiss et al., 2002; Addadi et al., 2003; Politi et al., 2009). Recent studies of carbonate precipitation kinetics have shown that the formation of an amorphous calcium carbonate (ACC) precursor permits significant $\mathrm{Mg}$ incorporation upon precipitation (Blue and Dove, 2015). The Mg content of the ACC depends strongly on $\mathrm{pH}$ and $\mathrm{Mg}$ concentration in solution. As ACC recrystallises, the resulting calcite is often characterised by relatively high Mg content (Blue et al., 2017). The precipitation of ACC itself requires very high supersaturation states in the $\mathrm{CaCO}_{3}$ system (Brečević and Nielsen, 1989) which, as previous studies have shown, can be attained in biomineralizing systems through the specific roles of biomolecules (Weiner and Dove, 2003). Amorphous precursor phases also feature commonly in the Fe(II)-carbonate system, in particular during homogeneous nucleation (Dideriksen et al., 2015; Jiang and Tosca., 2019). Such a pathway might be common in systems that achieve rapid supersaturation with respect to siderite. One example is through dissimilatory Fe-reduction where $\mathrm{Fe}^{2+}$, DIC, and total alkalinity are all simultaneously increased as the reaction progresses. In fact, experimental studies of dissimilatory Fe-reduction show morphological evidence for precipitation of siderite through an amorphous iron carbonate (AFC) precursor (Mortimer et al., 1997; Johnson et al., 2005; Dideriksen et al., 2015). 
499 be relatively indiscriminate toward trace element uptake (Littlewood et al., 2017). Our homogeneous 500 nucleation experiments producing siderite via an amorphous precursor phase, however, show no 501 discernible increase in Mg. EDS-SEM detects only a small peak for $\mathrm{Mg}$, barely above detection limit. 502 This is in agreement with other studies showing low apparent $\mathrm{Kd}$ of $\mathrm{Mg}$ in siderite (Thornber and 503 Nickel, 1976; Romanek et al., 2009). There is, however, one notable exception. Romanek et al 504 (2009) reported that Mg was only incorporated in to siderite structure when Mg starting 505 506 concentration was at modern seawater concentrations along with increased temperature and/or very large increases in carbonate alkalinity. However, it is unclear from their data whether $\mathrm{Mg}$ uptake is uniquely confined to siderite or instead to a Mg-rich carbonate phase, as the precipitates reported include multiple carbonate phases (i.e., siderite and magnesite or hydromagnesite).

\subsubsection{The role of temperature}

A number of studies have documented strong increases in the distribution coefficient describing Mg incorporation into calcite with temperature (Katz, 1973; Oomori et al., 1987; Mucci,

512 1987) Data for $\mathrm{Mg}^{2+}$ incorporation into siderite with temperature are far more limited. Data reported

513 by Romanek et al. (2009) show uptake of $\mathrm{Mg}$ at $70^{\circ} \mathrm{C}$, consistent with analogous predictions from 514 the $\mathrm{CaCO}_{3}$ system (Romanek et al., 2009). However, the precipitate identified was magnesite or 515 hydromagnesite, where Fe becomes a trace cation. Our $40^{\circ} \mathrm{C}$ experiment did not show $\mathrm{Mg}$ uptake 516 above the margin of error, however the precipitate formed at $55^{\circ} \mathrm{C}$ did co-precipitate $\mathrm{Mg}$ (consuming $517<2 \%$ of the initial concentration of $\mathrm{Mg}$ ). $\mathrm{Mg}$ concentrations used in our experiments were $40-50 \%$ 518 lower than Fe concentrations, and siderite was verified through XRD. Our limited data predict that 519 Mg uptake into siderite may continue to increase with increasing temperature. Therefore, in the 520 absence of other clear controls on Mg incorporation into siderite, we consider temperature as one of 521 the strongest controls on Mg concentrations in light of available data.

\subsection{Elemental composition of siderite as an indicator for paleo-environment}

One of the motivating scientific questions for this study is whether major element composition of siderite can be a reliable paleo-environmental indicator of pore water conditions, 
525 applicable to continental siderite studies through the Phanerozoic. Elemental compositions of 526 sphaerosiderites and other early diagenetic forms of siderite have been reported in many studies 527 (Mozley, 1989; Baker et al., 1996; Choi et al., 2003; Lim et al., 2004; Ufnar et al., 2004a; Robinson 528 et al., 2010; Ludvigson et al., 2013; Passey, 2014; Weibel et al., 2016). Some of these studies 529 report similar compositional trends, notably the repeated observation of $\mathrm{Mn}$ rich cores and $\mathrm{Ca}$ and 530 Mg rich outer rims/overgrowths (Curtis et al., 1986; Baker et al., 1996; Choi et al., 2003; Lim et al., 531 2004; Passey, 2014; Weibel et al., 2016). Other examples show only minor $\mathrm{Ca}, \mathrm{Mg}$ and $\mathrm{Mn}$ 532 substitution, with $\mathrm{Mn}$ incorporated the least (Choi et al., 2003; Robinson et al., 2010). Generally, 533 extensive $\mathrm{Ca}$ or $\mathrm{Mg}$ substitution, or extensive substitutions of cations other than $\mathrm{Fe}^{2+}$ have been 534 considered to indicate marine alteration (Mozley, 1989; Choi et al., 2003; Lim et al., 2004; Ufnar et 535 al., 2004a; Robinson et al., 2010; Weibel et al., 2016).

Our results indicate that the cation chemistry in solution alone has little bearing on elemental uptake in siderite. Instead, each trace cation ( $\mathrm{Mn}, \mathrm{Ca}, \mathrm{Mg})$ has a distinctly different uptake behaviour, affected by concentration, siderite saturation, presence of other competing cations, crystal structural controls, and growth mechanisms. For example, our results indicate that $\mathrm{Mn}$ 540 uptake from natural pore waters would be preferential even if $\mathrm{Ca}$ and $\mathrm{Mg}$ concentrations are high 541 (i.e., marine). Our results also indicate Fe/Mn ratios of the solution to be reflected in the Fe/Mn 542 ratios of the precipitate, and so high $\mathrm{Mn}$ substitution in geological siderite could simply indicate a 543 relatively high $\mathrm{Mn}$ content in the pore waters, and not impure siderites reflecting a marine influence 544 as suggested in Choi and Kim (2006). Further to this, our results imply that observations of "Ca-rich 545 siderite" are problematic and suffer from a lack of supporting evidence from the crystal growth 546 literature. The most parsimonious explanation is that other factors must be at play in a natural 547 system allowing Ca uptake into siderite. Comparison of experimental and geological examples of 548 siderite also sheds light on the origins of Mg enrichment in geological siderites. Given current 549 constraints on $\mathrm{Mg}$ incorporation and partition coefficients, rather than marine influences, Mg550 enriched overgrowths on rims of sphaerosiderites could perhaps be explained as products of 
551 diagenesis at shallow burial temperatures (Curtis et al., 1986; Mozley and Wersin, 1992; Baker et 552 al., 1996; Choi et al., 2003; Lim et al., 2004; Passey, 2014; Weibel et al., 2016).

Another origin of Mg-enriched compositions may be the presence of additional carbonate minerals. For instance, if Ca-Mg carbonate was present in the initial mineral assemblage, its recrystallisation to siderite is thermodynamically favoured if pore water $\mathrm{Fe}^{2+}$ concentrations are $5 \%$ of $\mathrm{Ca}^{2+}$ concentrations (Berner, 1971). Evidence of the growth of Ca-Mg carbonate and siderite in the same environment, including in the same concretion, can be found in wetland intertidal marsh sediments in Norfolk, UK, reported by Pye et al. (1990). The siderite cements from these concretions do not show Mg enrichment, instead Mg is enriched in the calcite cement growing in the same concretion. As most studies determine elemental compositions using electron microprobe, carbonate phases are typically not identified unambiguously (for instance, through XRD). Therefore, the reported Ca-Mg-Mn substitutions could alternatively be interpreted as physical mixtures of zoned carbonates, such as those examined by Pye et al. (1990).

Finally, one puzzling feature of geological siderite relates to the low, but non-negligible, background concentrations of $\mathrm{Mg}$ in almost all natural siderites (0.5 - $2 \mathrm{Wt} \%$ ) (Choi et al., 2003; Ufnar et al., 2004a; Robinson et al., 2010; Weibel et al., 2016). The two mechanisms of Mg enrichment (temperature increases or Ca-Mg carbonate replacement) suggested here do not readily apply to all examples where this has been observed. One remaining consideration could be the role of organic macromolecules during siderite precipitation. For instance, in calcium carbonate, it has been shown that carboxylated proteins, and other biomolecules, influence the uptake of $\mathrm{Mg}$ (Stephenson et al., 2008; Wang et al., 2009). In one study, carboxylated proteins with more of an affinity for binding $\mathrm{Ca}$ allowed production of Mg-rich amorphous calcium carbonate similar to high-

$573 \mathrm{Mg}$ calcite or dolomite. The ratios of $\mathrm{Mg} / \mathrm{Ca}$ depended on the binding properties of the organic 574 molecules involved (Wang et al., 2009). In a wetland system, rich in organic by-products, biological 575 macromolecules could be similarly influencing the growth of siderite, allowing deviation in cation uptake behaviour from those observed in classical abiotic crystal growth. Assessing this is beyond the scope of this study and merits further work, and whether or not the background Mg values noted 
578 in siderite could perhaps be a signal of biological activity must await further experimental and

579 observational evidence. Nonetheless, our study provides key abiotic constraints in elemental

580 uptake for siderite growth in saturations more analogous to natural waters than previous studies,

581 which can be used to better our understanding of the offsets between abiotic and biotic pathways.

582 The elemental composition of siderite clearly reflects a variety of growth conditions, and thus 583 cannot be solely used to infer palaeoenvironment. Instead, we suggest siderites should be studied 584 in the wider context of the sedimentology and stratigraphy of the units they grew within, with 585 detailed petrography and mineralogy of the spheres, as well as isotopic and elemental composition, 586 to have a broad understanding of their growth conditions, and assess their suitability for 587 palaeoclimate reconstruction.

\section{Conclusions}

Our experimental results provide new insight into the coprecipitation of $\mathrm{Mn}, \mathrm{Ca}$, and $\mathrm{Mg}$ during siderite nucleation and growth. This expanding experimental dataset emphasises the role of kinetic factors in regulating trace element incorporation into siderite, in particular surface structural controls during growth, transport phenomena, and temperature. In reality, because multiple factors regulate trace element incorporation, general and quantitative relationships between mineral chemistry and solution composition are difficult to ascertain and thus palaeoenvironmental interpretations should be made with these factors in mind.

Nevertheless, although experimental results provide valuable mechanistic information on the chemical controls on siderite composition, discrepancies between synthetic and natural systems still persist. Available data indicate that the apparent differences in the $\mathrm{Mg}$ and/or Ca concentration of both natural and synthetic siderite may in fact arise from incomplete mineralogical and geochemical characterisation. In order to address this issue more quantitatively, new and robust datasets, including complete characterisation of all crystalline carbonate phases within natural and synthetic samples, will be required. This should further illuminate the relationship between mineral chemistry 
603 and depositional environment and the potential for natural siderite specimens to reveal paleoclimatic 604 information through their chemical and/or isotopic composition.

\section{Acknowledgements}

This study was funded by NERC as part of the Doctoral Training Partnership in Environmental Research at the University of Oxford (NE/L002612/1). The authors would like to thank Rosalie Tostevin and Clancy Jiang for help with experimental setup, analyses and interesting discussions, and the three anonymous reviewers for thoughtful comments. The authors also thank Kat Clayton and Alice Barroll for assistance with XRD analyses, Gillian Mackinnon and John McArthur for help with ICP-OES analyses, and Jon Wade and Phil Gopon for assistance with SEM imaging.

\section{References}

Addadi L., Raz S. and Weiner S. (2003) Taking advantage of disorder: Amorphous calcium carbonate and its roles in biomineralization. Adv. Mater. 15, 959-970.

Azoulay I., Rémazeilles C. and Refait P. (2012) Determination of standard Gibbs free energy of formation of chukanovite and Pourbaix diagrams of iron in carbonated media. Corros. Sci. 58, 229-236. Available at: https://www.sciencedirect.com/science/article/pii/S0010938X12000674.

Bahrig B. (1989) Stable isotope composition of siderite as an indicator of the paleoenvironmental history of oil shale lakes. Palaeogeogr. Palaeoclimatol. Palaeoecol. 70, 139-151.

Baker J. C., Kassan J. and Hamilton P. J. (1996) Early diagenetic siderite as an indicator of depositional environment in the Triassic Rewan Group, southern Bowen Basin, eastern Australia. Sedimentology 43, 77-88. Available at: 10.1016/0031-0182(89)90085-0.

Berner R. A. (1971) Principles of Chemical Sedimentology., McGraw Hill.

Blue C. R. and Dove P. M. (2015) Chemical controls on the magnesium content of amorphous 
calcium carbonate. Geochim. Cosmochim. Acta 148, 23-33. Available at: https://www.sciencedirect.com/science/article/pii/S0016703714004980

Blue C. R., Giuffre A., Mergelsberg S., Han N., De Yoreo J. J. and Dove P. M. (2017) Chemical and physical controls on the transformation of amorphous calcium carbonate into crystalline CaCO3 polymorphs. Geochim. Cosmochim. Acta 196, 179-196. Available at: https://www.sciencedirect.com/science/article/pii/S0016703716305178

Brečević L. and Nielsen A. E. (1989) Solubility of amorphous calcium carbonate. J. Cryst. Growth 98, 504-510. Available at: https://www.sciencedirect.com/science/article/pii/0022024889901681

Burgess J. (1978) Metal ions in solution., Ellis Horwood Limited, Chichester.

Butler I. B., Schoonen M. A. A. and Rickard D. T. (1994) Removal of dissolved oxygen from water: A comparison of four common techniques. Talanta 41, 211-215. Available at: https://www.sciencedirect.com/science/article/pii/003991409480110X

Van Cappellan P. (1992) The formation of marine apatite: A kinetic study. Yale University.

Carothers W. W., Adami L. H. and Rosenbauer R. J. (1988) Experimental oxygen isotope fractionation between side\&-water and phosphoric acid liberated CO+iderite. Geochem n Cosmochim. Ada 52, 2445-2450.

Chen T., Neville A. and Yuan M. (2005) Assessing the effect of Mg2+ on CaCO3 scale formationbulk precipitation and surface deposition. J. Cryst. Growth 275, e1341-e1347. Available at: http://www.sciencedirect.com/science/article/pii/S0022024804016616.

Choi K. and Kim S. P. (2006) Late Quaternary evolution of macrotidal Kimpo tidal flat, Kyonggi Bay, west coast of Korea. Mar. Geol. 232, 17-34. 
648 Choi K. S., Khim B. K. and Woo K. S. (2003) Spherulitic siderites in the Holocene coastal deposits of Korea (eastern Yellow Sea): Elemental and isotopic composition and depositional environment. Mar. Geol. 202, 17-31.

Curtis C. D., Coleman M. L. and Love L. G. (1986) Pore water evolution during sediment burial from isotopic and mineral chemistry of calcite, dolomite and siderite concretions. Geochim. Cosmochim. Acta 50, 2321-2334.

Davis K. J., Dove P. M., Wasylenki L. E. and De Yoreo J. J. (2004) Morphological consequences of differential Mg2+ incorporation at structurally distinct steps on calcite. Am. Mineral. 89, 714720. Available at: http://dx.doi.org/10.2138/am-2004-5-605.

Dideriksen K., Frandsen C., Bovet N., Wallace A. F., Sel O., Arbour T., Navrotsky A., De Yoreo J. J. and Banfield J. F. (2015) Formation and transformation of a short range ordered iron carbonate precursor. Geochim. Cosmochim. Acta 164, 53-70. Available at: http://dx.doi.org/10.1016/j.gca.2015.05.005.

Driese S. G., Ludvigson G. A., Roberts J. A., Fowle D. A., González L. A., Smith J. J., Vulava V. M. and McKay L. D. (2010) Micromorphology and stable-isotope geochemistry of historical pedogenic siderite formed in PAH-contaminated alluvial clay soils, Tennessee, USA. J. Sediment. Res. 80, 943-954.

Dromgoole E. L. and Walter L. M. (1990) Iron and manganese incorporation into calcite: Effects of growth kinetics, temperature and solution chemistry. Chem. Geol. 81, 311-336. Available at: https://www.sciencedirect.com/science/article/pii/000925419090053A

Fisher Q. J., Raiswell R. and Marshall J. D. (1998) Siderite concretions from nonmarine shales (Westphalian A) of the Pennines, England; controls on their growth and composition. $J$. Sediment. Res. 68, 1034-1045. Available at: https://pubs.geoscienceworld.org/jsedres/article/68/5/1034-1045/98939 
672 Fosbøl P. L., Thomsen K. and Stenby E. H. (2010) Review and recommended thermodynamic 673 properties of $\mathrm{FeCO}_{3}$. Corros. Eng. Sci. Technol. 45, 115-135. Available at: http://www.tandfonline.com/doi/full/10.1179/174327808X286437

675 Glynn P. (2000) Solid-Solution Solubilities and Thermodynamics: Sulfates, Carbonates and Halides.

Goldschmidt J. R. (1983) Phase relations of rhombohedral carbonates. Rev. Mineral. Geochemistry 11, 49-76.

Gratz A. J., Hillner P. E. and Hansma P. K. (1993) Step dynamics and spiral growth on calcite. Geochim. Cosmochim. Acta 57, 491-495. Available at: https://www.sciencedirect.com/science/article/pii/0016703793904497

Jensen D. L., Boddum J. K., Tjell J. C. and Christensen T. H. (2002) The solubility of rhodochrosite ( MnCO 3 ) and siderite ( FeCO 3 ) in anaerobic aquatic environments. 17, 503-511.

Jiang C. Z. and Tosca N. J. (2019) Fe(II)-carbonate precipitation kinetics and the chemistry of anoxic ferruginous seawater. Earth Planet. Sci. Lett. 506, 231-242.

Jimenez-Lopez C. and Romanek C. S. (2004) Precipitation kinetics and carbon isotope partitioning of inorganic siderite at 25oC and 1 atm. Geochim. Cosmochim. Acta 68, 557-571.

Johnson C. M., Beard B. L., Klein C., Beukes N. J. and Roden E. E. (2008) Iron isotopes constrain biologic and abiologic processes in banded iron formation genesis. Geochim. Cosmochim.

Johnson C. M., Roden E. E., Welch S. A. and Beard B. L. (2005) Experimental constraints on Fe isotope fractionation during magnetite and Fe carbonate formation coupled to dissimilatory Acta 72, 151-169. hydrous ferric oxide reduction. Geochim. Cosmochim. Acta 69, 963-993. Available at: https://www.sciencedirect.com/science/article/pii/S0016703704005678 
695 Kandegedara A. and Rorabacher D. B. (1999) Noncomplexing tertiary amines as "better" buffers covering the range of $\mathrm{pH} 3-11$. Temperature dependence of their acid dissociation constants. Anal. Chem. 71, 3140-3144.

Katz A. (1973) The interaction of magnesium with calcite during crystal growth at $25-90^{\circ} \mathrm{C}$ and one atmosphere. Geochim. Cosmochim. Acta 37, 1563-1586. Available at: https://www.sciencedirect.com/science/article/pii/0016703773900914

Khim B.-K., Choi K.-S., Park Y.-A. and Oh J.-K. (1999) Occurrence of authigenic siderites in the Early Holocene coastal deposit in the west coast of Korea: an indicator of depositional environment. Geosci. J. 3, 163-170. Available at: http://link.springer.com/10.1007/BF02910272

Khim B.-K., Choi K.-S. and Park Y. A. (2000) Elemental composition of siderite grains in earlyHolocene deposits of Youngjong Island (west coast of Korea), and its palaeoenvironmental implications. Proc. Mar. Sci. 2, 205-217. Available at: https://www.sciencedirect.com/science/article/pii/S1568269200800170

Lim D. I., Jung H. S., Yang S. Y. and Yoo H. S. (2004) Sequential growth of early diagenetic freshwater siderites in the Holocene coastal deposits, Korea. Sediment. Geol. 169, 107-120.

Littlewood J. L., Shaw S., Peacock C. L., Bots P., Trivedi D. and Burke I. T. (2017) Mechanism of Enhanced Strontium Uptake into Calcite via an Amorphous Calcium Carbonate Crystallization Pathway. Cryst. Growth Des. 17, 1214-1223. Available at: http://pubs.acs.org/doi/10.1021/acs.cgd.6b01599

Ludvigson G. A., González L. A., Fowle D. A., Roberts J. A., Driese S. G., Villarreal M. A., Smith J. J. and Suarez M. B. (2013) Paleoclimatic Applications and Modern Process Studies of Pedogenic Siderite. New Front. Paleopedol. Terr. Paleoclimatology, 79-87.

Ludvigson G. A., González L. A., Metzger R. A., Witzke B. J., Brenner R. L., Murillo A. P. and White 
T. S. (1998) Meteoric sphaerosiderite lines and their use for paleohydrology and paleoclimatology. Geology 26, 1039-1042.

Mortimer R. J. G., Coleman M. L. and Rae J. E. (1997) Effect of bacteria on the elemental composition of early diagenetic siderite: Implications for palaeoenvironmental interpretations. Sedimentology 44, 759-765.

Mozley P. S. (1989) Relation between depositional environment and the elemental composition of early diagenetic siderite. Geology 17, 704-706.

Mozley P. S. and Wersin P. (1992) Isotopie composition of siderite as an indicator of depositional environment. Geology 20, 817-820.

Mucci A. (1987) Influence of temperature on the composition of magnesian calcite overgrowths precipitated from seawater. Geochim. Cosmochim. Acta 51, 1977-1984. Available at: https://www.sciencedirect.com/science/article/pii/0016703787901864

Nielsen M. H., Aloni S. and De Yoreo J. J. (2014) In situ TEM imaging of CaCO3 nucleation reveals coexistence of direct and indirect pathways. Science (80-. ). 345, 1158 LP - 1162. Available at: http://science.sciencemag.org/content/345/6201/1158.abstract.

Oomori T., Kaneshima H., Maezato Y. and Kitano Y. (1987) Distribution coefficient of Mg2+ ions between calcite and solution at $10-50^{\circ} \mathrm{C}$. Mar. Chem. 20, 327-336. Available at: https://www.sciencedirect.com/science/article/pii/0304420387900661

Paquette J. and Reeder R. J. (1990) New type of compositional zoning in calcite: Insights into crystal-growth mechanisms. Geology 18, 1244-1247. Available at: https://pubs.geoscienceworld.org/geology/article/18/12/1244-1247/198549

Paquette J. and Reeder R. J. (1995) Relationship between surface structure, growth mechanism, and trace element incorporation in calcite. Geochim. Cosmochim. Acta 59, 735-749. Available 

at: https://www.sciencedirect.com/science/article/pii/001670379500004J

742 Passey S. R. (2014) The habit and origin of siderite spherules in the Eocene coal-bearing Prestfjall Formation, Faroe Islands. Int. J. Coal Geol. 122, 76-90. Available at: https://www.sciencedirect.com/science/article/pii/S0166516213002760

Politi Y., Arad T., Klein E., Weiner S. and Addadi L. (2009) Sea Urchin Spine CalciteForms via a Transient Amorphous Calcium Carbonate Phase. Science 306, 1161-1164. Available at: http://www.ncbi.nlm.nih.gov/pubmed/15539597.

Postma D. (1980) Formation of siderite and vivianite and the pore-water composition of a Recent bog sediment in Denmark. Chem. Geol. 31, 225-244.

Pye K., Dickson J. A. D., Schiavon N., Coleman M. L. and Cox M. (1990) Formation of siderite-Mgcalcite-iron sulphide concretions in intertidal marsh and sandflat sediments, north Norfolk, England. Sedimentology 37, 325-343.

Rakovan J. and Reeder R. J. (1996) Intracrystalline rare earth element distributions in apatite: Surface structural influences on incorporation during growth. Geochim. Cosmochim. Acta 60, 4435-4445. Available at: https://www.sciencedirect.com/science/article/pii/S001670379600244X

Reeder R. J. (1983) Crystal chemistry of the rhombohedral carbonates. Rev. Mineral. Geochemistry $11,1-47$.

Reeder R. J. (1996) Interaction of divalent cobalt, zinc, cadmium, and barium with the calcite surface during layer growth. Geochim. Cosmochim. Acta 60, 1543-1552. Available at: https://www.sciencedirect.com/science/article/pii/0016703796000348

Reeder R. J., Fagioli R. O. and Meyers W. J. (1990) Oscillatory zoning of Mn in solution-grown calcite crystals. Earth-Science Rev. 29, 39-46. Available at: 
Reeder R. J. and Rakovan J. (1999) Surface Structural Controls on Trace Element Incorporation during Crystal Growth. In Growth, Dissolution and Pattern Formation in Geosystems (eds. B. Jamtveit and P. Meakin). Springer Netherlands, Dordrecht. pp. 143-162. Available at: https://doi.org/10.1007/978-94-015-9179-9_6.

Rimstidt J. D., Balog A. and Webb J. (1998) Distribution of trace elements between carbonate minerals and aqueous solutions. Geochim. Cosmochim. Acta 62, 1851-1863. Available at: https://www.sciencedirect.com/science/article/pii/S0016703798001252

Robinson S. A., Scotchman J. I., White T. S. and Atkinson T. C. (2010) Constraints on palaeoenvironments in the Lower Cretaceous Wealden of southern England, from the geochemistry of sphaerosiderites. J. Geol. Soc. London. 167, 303-311.

Rodriguez-Navarro C., Burgos Cara A., Elert K., Putnis C. V. and Ruiz-Agudo E. (2016) Direct Nanoscale Imaging Reveals the Growth of Calcite Crystals via Amorphous Nanoparticles. Cryst. Growth Des. 16, 1850-1860.

Romanek C. S., Jiménez-López C., Navarro A. R., Sánchez-Román M., Sahai N. and Coleman M. (2009) Inorganic synthesis of Fe-Ca-Mg carbonates at low temperature. Geochim. Cosmochim. Acta 73, 5361-5376.

Sel O., Radha A. V., Dideriksen K. and Navrotsky A. (2012) Amorphous iron (II) carbonate: Crystallization energetics and comparison to other carbonate minerals related to $\mathrm{CO} 2$ sequestration. Geochim. Cosmochim. Acta 87, 61-68. Available at: https://www.sciencedirect.com/science/article/pii/S0016703712001536

Steefel C. I. and Van Cappellen P. (1990) A new kinetic approach to modeling water-rock interaction: The role of nucleation, precursors, and Ostwald ripening. Geochim. Cosmochim. 
Acta 54, 2657-2677. Available at:

https://www.sciencedirect.com/science/article/pii/0016703790900034

Steinmann P. and Shotyk W. (1997) Chemical composition, pH, and redox state of sulfur and iron in complete vertical porewater profiles from two Sphagnum peat bogs, Jura Mountains, Switzerland. Geochim. Cosmochim. Acta 61, 1143-1163.

Stephenson A., DeYoreo J., Wu L., Wu K., Hoyer J. and Dove P. (2008) Peptides Enhance Magnesium Origins of Vital Effects. Science (80-. ). 322, 724-727.

Suarez M. B., González L. A., Ludvigson G. A., Vega F. J. and Alvarado-Ortega J. (2009) Isotopic composition of low-latitude paleoprecipitation during the Early Cretaceous. Geol. Soc. Am. Bull. 121, 1584-1595. Available at: https://pubs.geoscienceworld.org/gsabulletin/article/121/11$12 / 1584-1595 / 2350$

Sunagawa I. (2007) Crystals : Growth, morphology, and perfection., Cambridge University Press.

Teng H. H., Dove P. M. and De Yoreo J. J. (2000) Review on MAC Protocols for Underwater Acoustic Networks. Geochemica Cosmochem. Acta 64, 2255-2266. Available at: https://irjet.net/archives/V4/i1//RJET-V4I1310.pdf.

Thornber M. R. and Nickel E. H. (1976) Supergene alteration of sulphides. III. The composition of associated carbonates. Chem. Geol. 17, 45-72. Available at: https://www.sciencedirect.com/science/article/pii/0009254176900218

Ufnar D. F., Gonzalez L. A., Ludvigson G. A., Brenner R. L. and Witzkes B. J. (2004a) Diagenetic overprinting of the sphaerosiderite palaeoclimate proxy: Are records of pedogenic groundwater ??180 values preserved? Sedimentology 51, 127-144.

Ufnar D. F., Ludvigson G. A., González L. A., Brenner R. L. and Witzke B. J. (2004b) High latitude meteoric $\delta 180$ compositions: Paleosol siderite in the Middle Cretaceous Nanushuk Formation, 
North Slope, Alaska. Geol. Soc. Am. Bull. 116, 463. Available at: https://pubs.geoscienceworld.org/gsabulletin/article/116/3-4/463-473/2072

Wang D., Wallace A. F., De Yoreo J. J. and Dove P. M. (2009) Carboxylated molecules regulate magnesium content of amorphous calcium carbonates during calcification. Proc. Natl. Acad. Sci. 106, 21511-21516.

Wang Y. and Merino E. (1992) Dynamic model of oscillatory zoning of trace elements in calcite: Double layer, inhibition, and self-organization. Geochim. Cosmochim. Acta 56, 587-596. Available at: https://www.sciencedirect.com/science/article/pii/001670379290083U

Weibel R., Lindstr??m S., Pedersen G. K., Johansson L., Dybkj??r K., Whitehouse M. J., Boyce A. J. and Leng M. J. (2016) Groundwater table fluctuations recorded in zonation of microbial siderites from end-Triassic strata. Sediment. Geol. 342, 45-65. Available at: http://dx.doi.org/10.1016/j.sedgeo.2016.06.009.

Weiner S. and Dove P. M. (2003) An Overview of Biomineralization Processes and the Problem of the Vital Effect. Rev. Mineral. Geochemistry 54, 1-29. Available at: https://pubs.geoscienceworld.org/rimg/article/54/1/1-29/87485

Weiss I. M., Tuross N., Addadi L. and Weiner S. (2002) Mollusc larval shell formation: Amorphous calcium carbonate is a precursor phase for aragonite. J. Exp. Zool. 293, 478-491.

Zhang Y. and Dawe R. A. (2000) Influence of Mg2+ on the kinetics of calcite precipitation and calcite crystal morphology. Chem. Geol. 163, 129-138. Available at: http://www.sciencedirect.com/science/article/pii/S0009254199000972. 